more frequently found about the abodes of civilization, than in the solitude of the forest. In Bretton woods several woodpeckers were shot by our party, all of them very beautiful species, and among the rest picus tridactylus remarkably distinguished from the rest of his family by the number of his toes. The partridge (tetrao umbellus) we frequently scardd. This bird, as wcll as a species of plover or of tringa, have been seen in the upper or bald part of the mountain.

We were told by the people in Bartlett and Conway, that the rattlesnake (crotalus horridus) infests the rocks and sides of the hills in great numbers, and that twenty of these reptiles had been killed in a day. They even approach dwelling $\therefore$ houses, at the doors of which they have been killed. The inhabitants regard them with little apprehension, since they are represented as slow and clumsy in their motions, and as always giving notice on being approached, by a loud and long continued rattle, resembling very much the singing of a locust. We saw none of these serpents, and heard of no injury sustained by any one from their bite.

The insects which we ogserved at the top of the mountain, were as numerous and various as in any place below. Among them were species of Phalazna, Cerambyx, Coccinella, Buprestis, Cimex and Tenthredo. The most splendid of our native butterflies Papilio Turnus 8 was fluttering near us while we remained on the summit.

\title{
CASE OF AMPUTATION OF A PART OF THE FOOT, WITH REMARKS.
}

BY GEORGE HAYWARD, M. D.

There is no particular description, I believe in any system of Surgery, of the method to be pursued in amputating a portion of the foot. This is the more remarkable, as the bones of the tarsus and metatarsus are often so much diseased from frost, and other causes, as to require removal. 'To do this without amputating the whole foot, is extremely important to the patient. In the "Practical Observations in Surgery" by Mr. Hey, of Iseeds, there is an account of two cases, in which he performed 
this operation, in a manner so novel and ingenious, that surgeons in Great Britain; and this country, have given him the credit of inventing it, and the operation is now known by his name. 'The merit however, of his invention, consists only in the manner in which he covered the stump, as the method of amputating at the articulations of the foot, is described by M. Brasdor, in the XVth Volume of the Memoirs of the French Academy of Surgery. Prior to the publication of this memoir, it was almost the invariable custom of Surgeons, to amputate above the ankle, for diseases of the tarsus and metatarsus. But since that period, operations at the articulations of the foot, have become frequent, though rarely at any other part, as Surgeons seem to be apprehensive that if they are performed by sawing through the bones, the violence done to them will be so great, that exfoliation will generally ensue. Richerand, Dupuytren and Roux, have each given directions by which the articulations may be found; and it appears, by the analysis of the labours of the class of Physical Sciences of the Institute of France, for the year 1815, that still further rules have been laid down by $\mathbf{M}$. Lisfrane St. Martin, in a memoir read to that body during the year. This desire to point out the precise situation of the articulations, proves that it was considered important, that operations should be performed at those places.

The following case is related, merely to shew that exfoliation loes not necessarily take place, when the bones are sawed through, and if the same result should generally be found to follow, it is evident, that in many cases of diseased foot, such as where a small portion only of the tarsal or metatarsal bones is affected, this operation can be used with more advantage to the patient and more ease to the operator, than even that of Hey.

CASF.

Benjamin Kellum, aged about 30, had for five years laboured under a disease of the bones of the foot, originally occasioned by frost. During that period, various attempts to cure it had been made by different Surgeons without effect, and amputation had been repeatedly recommended, but the patient was unwilling to submit to it. A short time, however, previous to the operation, the pain was so. great, and his health had become so much impaired, that he was desirous of having the disensed parts removed. When I examined the foot, I found that on the 
upper surface, there were two small openings, through which there was a considerable discharge of bloody pus; and by passing a probe into either of them, it came into contact with the cunieform bones which were denuded and diseased at their union, with the metatarsal bones. It was evident, from the state of the parts, that it was impossible to perform the operation recommended by $\mathrm{Hey}$, of disarticulating the foot at the junction of the tarsal and metatarsal bones, and sawing off the projecting portion of the cuneiform bone of the great toe. The operation was therefore performed in the following manner. An incision was first made across the foot, as near the diseased parts as possible. The knife was then passed between the bones and muscles on the under part of the foot, and brought out at the opposite side; it was then carried down to the first joint of the toes, 80 as completely to separate the integuments and muscles from the bones. The integuments at the first incision were then dissected up about half an inch, and the bones, sawed through at that place. The under flap not being yet divided, the anterior part of the foot was raised up, so as to be able.to determine how much flap it was necessary to save. This being ascertained by bringing the muscles and integuments in contact with the stump, the diseased part of the foot was removed; the anterior tibial artery, being the only one that required a ligature, was tied, and the flap was secured in its place by two stitches. The stump was dressed in the ordinary manner. For the first ten lnya, every appearance was favourable; healthy pus was secreted, considerable adhesions had taken place, and at the end of that time, the ligature from the artery and both the stitches had come away. A day or two after this, the patient complained of pain on the inner ankle, the part was red and considerably swelled. ' $\Lambda$ pplications of lead water were made to it, but in about three days from its first appearance, it was found necessary to open it, when it discharged a large quantity of pus. For five weeks from this time matter continued to form on the outer and inner ankle, and four openings were made to evacuate it, one of them nearly six inches above the place where the operation was performed. The discharge became so great, that the patient's health, which was feeble beforo the amputation, declined ranidly, and the cdges of the wound, discovered no disposition to unite. Powder of Bark, and Wine 
in large quantities were given, and the patient was put upon a generous diet. In a short time his health was improved, the discharge diminished, and the edges of the wound were considerably united, so that in nine weeks from the operation, the stuinp was healed, excepting in three places, about the size of a small pea, from which there was a pretty copious discharge, for two months longer, of pus and serum. This however abated, and in a short time yielded so far to friction, compresses and the application of cold water, that at the expiration of five months, there was only a small opening, from which a few drops of serum were discharged every day. About this time the patient began to bear more weight on that leg, and by the assistance of a half boot which supported his ankle, he was soon enabled to stand and walk with firmness, ease and security. At first he was compelled to use a crutch, and he now makes use of a cane, through he can walk tolerably well without one. The last opening closed a few weeks after he began to walk, so that the cicatrix is now firm in every part. His health is much better than it has been for five years.

Though the bones proved upon examination, after the operation " to be very much diseased, there was no exfoliation. It is probable, that if amputation had been performed some years before, the stump might have been healed in a few weeks; but as the secretion of pus had continued so long, it was difficult to overcome the morbid action of the vessels.

\section{MORBID ANATOMY.}

Case of Chronic Diarrhaea, accompanied by the discharge of some peculiar substances.

BY DR. JEREMY STIMSON, OF DEDHAM.

$\mathrm{M}_{\text {ARY-ANN }} \mathrm{C}_{\mathrm{LAP}}$ came under my care on the 6th of May, 1816; at which time she was ten years of age. Her discase commenced in July, 1814, and had continued from that period with great uniformity of symptoms. She had had a constant diar-

*I performed the operation at the Boston Alms-House, January 7th, 1816. 